\title{
Effects of physicochemical properties on heavy metal, magnetic susceptibility and natural radionuclides with statistical approach in the Chennai coastal sediment of east coast of Tamilnadu, India
}

\author{
R. Ravisankar ${ }^{1} \cdot$ M. Tholkappian ${ }^{1,2} \cdot$ A. Chandrasekaran ${ }^{3} \cdot$ P. Eswaran ${ }^{4} \cdot$ Atef El-Taher $^{5}$
}

Received: 27 January 2019 / Accepted: 1 August 2019 / Published online: 10 August 2019

(c) The Author(s) 2019

\begin{abstract}
The aim of the study was to determine the effects of physicochemical properties of sediment samples on the heavy metal, magnetic susceptibility, and natural radioactivity concentration. Spectroscopic techniques like energy-dispersive X-ray fluorescence, dual-frequency susceptibility meter, and gamma ray spectrometry measurements are commonly employed for the determination of heavy metals, magnetic particle, and radioactivity concentration in sediment sample collected from Pulicat Lake to Vadanemmeli, of Chennai Coast, Tamilnadu. The relations between the physical and chemical properties and studied parameters of sediment samples were mainly clarified with Pearson correlation, factor, and cluster analysis. Silt content was the most effective parameter on the studied parameter. The results are discussed and the conclusion is drawn.
\end{abstract}

Keywords Sediment $\cdot$ Physicochemical properties $\cdot$ Heavy metal $\cdot$ Magnetic susceptibility $\cdot$ Natural radioactivity · Multivariate analysis

\section{Introduction}

Grain size analysis is the most basic property used by geologists to study transport phenomenon such as transport and deposit of sediments. This property also helps the ecologists in the study of habitats and engineers in the study of permeability. Geochemists use this property extensively to study kinetic reactions and hydrologists use it to study subsurface fluid flow (Blatt et al. 1972; McCave and Syvitski 1991).

\section{R. Ravisankar}

ravisankarphysics@gmail.com

1 Post Graduate and Research Department of Physics, Government Arts College, Tiruvannamalai, Tamilnadu 606603, India

2 Department of Physics, Sri Vari College of Education, Then Arasampattu, Tiruvannamalai, Tamilnadu 606611, India

3 Department of Physics, SSN College of Engineering, Kalavakkam, Chennai, Tamilnadu 603110, India

4 Department of Physics, Saveetha Institute of Medical and Technical Sciences, Saveetha School of Engineering, Thandalam, Chennai, Tamilnadu 602105, India

5 Department of Physics, Al Azhar University, Assiut, Egypt
The mechanical analysis of the sediment not just for the nature of the sediment, also to understand the physical properties of the sediments and revealed the relationship and the effect of the grain size, source materials and depositional environment. Some investigations have shown the dependence of radionuclide concentrations, heavy metal, and magnetic susceptibility on grain size (Ramasamy et al. 2014; Paramasivam et al. 2015; Melquiades et al. 2014).

Sediment texture indicates the characteristics of soil such as clay, silt, and proportion of sand. In the solid phase, clay has the largest surface of contact, and hence, it easily adsorbs metals. Water permeability is higher in sandy sediments due to the presence of sand granules. Silts are intermediate in granulometry aggregate light particles. Texture of the sediment soil is determined using densitometry.

Spectroscopic techniques like energy-dispersive X-ray fluorescence (EDXRF), dual-frequency susceptibility meter, and gamma ray spectrometry measurements are commonly employed for the determination of heavy metals, magnetic particle, and radioactivity concentration in sediments. These techniques are not conventionally used for texture determination. However, it is known that metals used to have a greater affinity for smaller particles and organic compounds, i.e., for clay sediments, but it depends on geochemical conditions. 
The main aim of this study was to present a method for physicochemical parameters combining three spectroscopy techniques with multivariate analysis. Specifically, data were used from energy-dispersive X-ray fluorescence (EDXRF), dual-frequency susceptibility meter, and gamma ray spectrometry measurements in sediment samples which were combined with principal component analysis for exploratory data analysis and with cluster analysis for classification.

\section{Materials and methods}

\section{Sediment sampling}

Twenty-two sediment samples were collected from Chennai Coast along the Bay of Bengal Coastline (Pulicat Lake to Vadanemmeli) in Southeastern India using a Peterson grab sampler from $10 \mathrm{~m}$ water depths during the pre-monsoon season. All sampling points were located parallel to the shoreline as shown in Fig. 1. The grab sampler collects the samples at $10 \mathrm{~cm}$ below the seabed in all sampling points. Around $25-\mathrm{cm}$-thick subsurface samples from the seabed were collected by the grab. From the grabbed samples, 10-cm-thick sediment layer was sampled from the middle of the grab to avoid metal contamination by the jaws of the grab.

Table 1 shows the geographic coordinates (latitudes and longitudes) of the various sampling locations. A hand-held Global Positioning System-Garmin oregon 550-was used in measuring the coordinates of the sampling points. Interstation spacing was maintained at 3NM (nautical mile).

Coastal craft was utilized for collecting samples at each station. After traveling to the beach by road, the sample collection team hires a boat from artisanal fishermen, who convey them to the sampling points after about $60 \mathrm{~min}$ of sailing. The Peterson grab sampler is suitable for sampling near-shore sea bed sediments, particularly, in locations where the sea bed is dominated by sandy, silt, and/or gravelly sediments. This technique is the conventional method of sampling shallow sea bottom sediments (Sly 1969; Ingham 1975; Ravisankar et al. 2015).

The samples were immediately transferred to polythene bags to prevent them from being in continuous contact with the metallic dredge. The top layer of the samples was scooped with an acid-washed plastic spatula. The samples were stored in plastic bags and kept in refrigeration or at
Fig. 1 Sampling locations Pulicat Lake to Vadnemmeli of Chennai coast

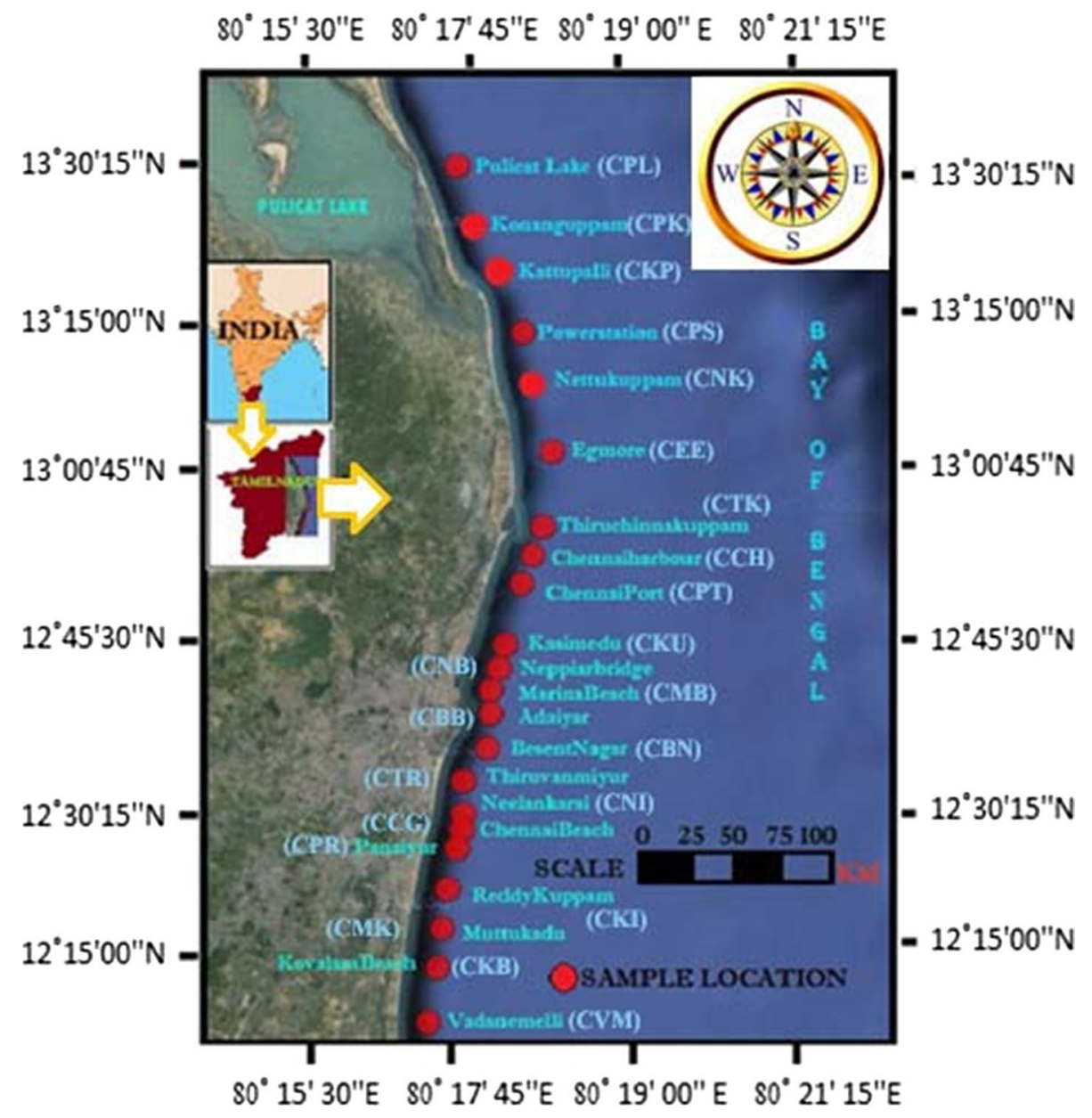


Table 1 Geographical latitude and longitude for the sampling locations

\begin{tabular}{|c|c|c|c|c|}
\hline S.No & Location & Sample ID & Latitude & Longitude \\
\hline 1 & Pulicat Lake & CPL & $13^{\circ} 34^{\prime} 3.82^{\prime \prime} \mathrm{N}$ & $80^{\circ} 18^{\prime} 0.75^{\prime \prime} \mathrm{E}$ \\
\hline 2 & Pulicat (Koonangkuppam) & CPK & $13^{\circ} 25^{\prime} 31.42^{\prime \prime} \mathrm{N}$ & $80^{\circ} 21^{\prime} 26.12^{\prime \prime} \mathrm{E}$ \\
\hline 3 & Kattupalli & CKP & $13^{\circ} 19^{\prime} 27.33^{\prime \prime} \mathrm{N}$ & $80^{\circ} 22^{\prime} 51.77^{\prime \prime} \mathrm{E}$ \\
\hline 4 & Power Station & CPS & $13^{\circ} 15^{\prime} 35.37^{\prime \prime} \mathrm{N}$ & $80^{\circ} 22^{\prime} 21.94^{\prime \prime} \mathrm{E}$ \\
\hline 5 & Nettukuppam & $\mathrm{CNK}$ & $13^{\circ} 14^{\prime} 10.50^{\prime \prime} \mathrm{N}$ & $80^{\circ} 21^{\prime} 53.23^{\prime \prime} \mathrm{E}$ \\
\hline 6 & Ennore & CEE & $13^{\circ} 12^{\prime} 41.88^{\prime \prime} \mathrm{N}$ & $80^{\circ} 21^{\prime} 18.71^{\prime \prime} \mathrm{E}$ \\
\hline 7 & Tiruchinnakuppam & CTK & $13^{\circ} 9^{\prime} 36.02^{\prime \prime} \mathrm{N}$ & $80^{\circ} 20^{\prime} 32.34^{\prime \prime} \mathrm{E}$ \\
\hline 8 & Chennai Harbor (Nagooranthottam) & $\mathrm{CCH}$ & $13^{\circ} 8^{\prime} 20.61^{\prime \prime} \mathrm{N}$ & $80^{\circ} 20^{\prime} 8.02^{\prime \prime} \mathrm{E}$ \\
\hline 9 & Chennai Port (Kasimedu Fishing Harbour) & CPT & $13^{\circ} 6^{\prime} 5.45^{\prime \prime} \mathrm{N}$ & $80^{\circ} 19^{\prime} 44.78^{\prime \prime} \mathrm{E}$ \\
\hline 10 & Kasimedu-Tondiarpet & $\mathrm{CKU}$ & $13^{\circ} 7^{\prime} 14.61^{\prime \prime} \mathrm{N}$ & $80^{\circ} 19^{\prime} 44.04^{\prime \prime} \mathrm{E}$ \\
\hline 11 & Neppiar Bridge & CNB & $13^{\circ} 4^{\prime} 17.77^{\prime \prime} \mathrm{N}$ & $80^{\circ} 19^{\prime} 34.47^{\prime \prime} \mathrm{E}$ \\
\hline 12 & Marina Beach & $\mathrm{CMB}$ & $13^{\circ} 2^{\prime} 34.23^{\prime \prime} \mathrm{N}$ & $80^{\circ} 18^{\prime} 20.02^{\prime \prime} \mathrm{E}$ \\
\hline 13 & Broken Beach (Adaiyaralamaram) & $\mathrm{CBB}$ & $13^{\circ} 0^{\prime} 54.40^{\prime \prime} \mathrm{N}$ & $80^{\circ} 18^{\prime} 21.48^{\prime \prime} \mathrm{E}$ \\
\hline 14 & Besent Nagar & $\mathrm{CBN}$ & $13^{\circ} 0^{\prime} 8.21^{\prime \prime} \mathrm{N}$ & $80^{\circ} 18^{\prime} 17.37^{\prime \prime} \mathrm{E}$ \\
\hline 15 & Thiruvanmiyur & CTR & $12^{\circ} 59^{\prime} 8.39^{\prime \prime} \mathrm{N}$ & $80^{\circ} 18^{\prime} 0.98^{\prime \prime} \mathrm{E}$ \\
\hline 16 & Neelankarai & $\mathrm{CNI}$ & $12^{\circ} 57^{\prime} 2.18^{\prime \prime} \mathrm{N}$ & $80^{\circ} 17^{\prime} 29.61^{\prime \prime} \mathrm{E}$ \\
\hline 17 & Chennai Golden Beach & $\mathrm{CCG}$ & $12^{\circ} 55^{\prime} 3.90^{\prime \prime} \mathrm{N}$ & $80^{\circ} 17^{\prime} 16.44^{\prime \prime} \mathrm{E}$ \\
\hline 18 & Panaiyur & CPR & $12^{\circ} 53^{\prime} 2.32^{\prime \prime} \mathrm{N}$ & $80^{\circ} 17^{\prime} 4.18^{\prime \prime} \mathrm{E}$ \\
\hline 19 & Kanathursunami, (Reddykuppam) & CKI & $12^{\circ} 50^{\prime} 12.66^{\prime \prime} \mathrm{N}$ & $80^{\circ} 16^{\prime} 34.01^{\prime \prime} \mathrm{E}$ \\
\hline 20 & Muttukaadu (Karikattukuppam) & CMK & $12^{\circ} 48^{\prime} 36.74^{\prime \prime} \mathrm{N}$ & $80^{\circ} 16^{\prime} 40.72^{\prime \prime} \mathrm{E}$ \\
\hline 21 & Kovalam Beach & $\mathrm{CKB}$ & $12^{\circ} 47^{\prime} 24.36^{\prime \prime} \mathrm{N}$ & $80^{\circ} 16^{\prime} 48.33^{\prime \prime} \mathrm{E}$ \\
\hline 22 & Vadanemmeli, (Puthiyakalpakkam) & CVM & $12^{\circ} 44^{\prime} 59.05^{\prime \prime} \mathrm{N}$ & $80^{\circ} 16^{\prime} 39.20^{\prime \prime} \mathrm{E}$ \\
\hline
\end{tabular}

$4{ }^{\circ} \mathrm{C}$. They were subsampled using coning and quartering method (Ravisankar et al. 2015). The subsamples were air-dried and larger stone fragments or shells were manually removed.

\section{Sample preparation for different analysis}

\section{EDXRF technique}

The samples were oven dried at $105{ }^{\circ} \mathrm{C}$ for constant weight and sieved using a $63-\mu \mathrm{m}$ sieve. The use of grain sizes of $<63 \mu \mathrm{m}$, in such analysis, has several advantages: (1) Heavy metals are mainly linked to silt and clay particles, (2) this grain size is like that of suspended matter in water, and (3) it has been used in many studies on heavy metal contamination.

Then the samples were grinded to a fine powder using an agate mortar. All the pulverized samples were stored in desiccators until they were analyzed. One gram of the fine ground sample and $0.5 \mathrm{~g}$ of boric acid $\left(\mathrm{H}_{3} \mathrm{BO}_{3}\right)$ were mixed. The mixture was thoroughly ground and pressed to a pellet of $25 \mathrm{~mm}$ diameter using a 20-ton hydraulic press (Ravisankar et al. 2011).

\section{Magnetic studies}

In the laboratory, the samples were air-dried at room temperature to reduce mass contribution of water and to avoid any chemical reactions. They were then sieved using a 1-mm sieve mesh to remove particles such as glass, plant debris, refuse, and small stones. The sieved samples were stored in a plastic container for further laboratory measurements.

\section{Natural radioactivity measurements}

The samples were air-dried at $105{ }^{\circ} \mathrm{C}$ for constant weight and sieved through $250-\mu$ mesh. The homogenized sample was placed in a 250-g airtight PVC container. The inner lid was placed and closed tightly with outer cap. Each sediment sample container was left for at least 5 weeks to reach secular equilibrium between ${ }^{238} \mathrm{U}\left({ }^{226} \mathrm{Ra}\right)$ and ${ }^{232} \mathrm{Th}\left({ }^{228} \mathrm{Ra}\right)$ and their progenies.

\section{Granulometric analysis}

The samples were examined to measure their granulometric fractions such as contents of sand, silt, and clay. About $100 \mathrm{~g}$ of sediment was taken for separation of sand, silt, 
and clay fractions by sieving (Suresh et al. 2011). In order to determine the organic matter $(\mathrm{OM})$ in the samples, $20 \mathrm{~g}$ of bulk samples and 5-10 $\mathrm{g}$ of various grain sized samples were taken for analysis.

\section{Sample analysis for different techniques}

\section{EDXRF technique}

The pellets were analyzed using EDXRF spectrometer (model EX-6600SDD) manufactured by Xenemetrix, Israel). This instrument is available at Environmental and Safety Division, Indira Gandhi Centre for Atomic Research (IGCAR), Kalpakkam, Tamilnadu. This spectrometer is equipped with a side window X-ray tube $(370 \mathrm{~W})$ that has Rhodium as anode. The power specifications of the tube are 3-60 kV and 10-5833 $\mu \mathrm{A}$. Selection of filters, tube voltage, sample position, and current are fully computer controlled and having an energy resolution of $136 \mathrm{eV} \pm 5 \mathrm{eV}$ Mn customizable. The silicon drift detector $25 \mathrm{~mm}$ X-ray and 10-sample turret enables the instrument to position and analyze 10 samples concurrently. Quantitative analysis was conducted with the help of in-built nEXT software. A standard soil sample (NIST SRM 2709a) was used as reference material for standardizing the instrument. This soil standard was obtained from a follow field in San Joaquin valley, central California.

\section{Magnetic susceptibility $(\chi)$ measurements}

The magnetic susceptibility measurements were then carried out on the sieved samples packaged in a 10-ml plastic container at laboratory temperature. Measurements of magnetic susceptibility were made at both low $(0.465 \mathrm{kHz})$ and high $(4.65 \mathrm{kHz})$ frequencies using MS2B dual-frequency susceptibility meter linked to a computer operated using a Multisus2 software. All measurements were conducted at the 1.0 sensitivity setting. Each sample was measured five times in two different frequencies (low and high) and an average is calculated.

\section{Gamma ray spectrometry}

Sediment samples were subjected to gamma spectral analysis with a counting time of $20,000 \mathrm{~s}$. A 3 inch $\times 3$ inch NaI (Tl) detector was employed with adequate lead shielding which reduced the background by a factor of about $95 \%$. The concentrations of various radionuclides of interest were determined in $\mathrm{Bq} / \mathrm{kg}$ using the count spectra. To find out the radioactivity content in sediment samples, the systems have to be efficiency calibrated for various energies of interest in the selected sample geometry. As the measurement is for the natural radioactive elements ${ }^{40} \mathrm{~K}$, uranium, and thorium, the gamma energies selected are $1460 \mathrm{keV}$ for ${ }^{40} \mathrm{~K}, 1763 \mathrm{keV}$ (from daughter product ${ }^{214} \mathrm{Bi}$ ) for uranium, and $2614 \mathrm{keV}$ (from daughter product ${ }^{208} \mathrm{Tl}$ ) for thorium. The detection limit of $\mathrm{NaI}(\mathrm{Tl})$ detector system for ${ }^{40} \mathrm{~K},{ }^{238} \mathrm{U}$, and ${ }^{232} \mathrm{Th}$ is $8.50,2.21$, and $2.11 \mathrm{~Bq} / \mathrm{kg}$, respectively, for a counting time of $20,000 \mathrm{~s}$.

\section{Determination of physicochemical properties of sediments}

\section{Particle size analysis}

A particle size analysis of sediments is carried out by mechanical sieve shaker method. This method is very efficient to find the percentage of sand, silt, and clay in sediments (Sonaye and Baxi 2012). A typical mechanical sieve shaker is shown in Fig. 2.

Sieves of different sizes $(12 \mathrm{~mm}, 150 \mathrm{~mm}$, and $200 \mathrm{~mm}$ ) assembled in ascending order in a sieve shaker. A weighed sediment sample is poured into the top sieve which has the largest screen openings. Each lower sieve in the column has smaller openings than the one above. At the base is a round pan called the receiver. The column is typically placed in a mechanical shaker. The shaker shakes the column, usually for 3-5 min. After the shaking is complete, the sample on each sieve is weighed. Then, percentage of sand, slit and clay in sediment is calculated using the following equation:

$\%$ Of sand, slit and clay $=\frac{W_{\text {Sieve }}}{W_{\text {Total }}} \times 100 \%$

where $W_{\text {Sieve }}$ is a mass of sample retained in the sieve and $W_{\text {Total }}$ is a total mass of sample.

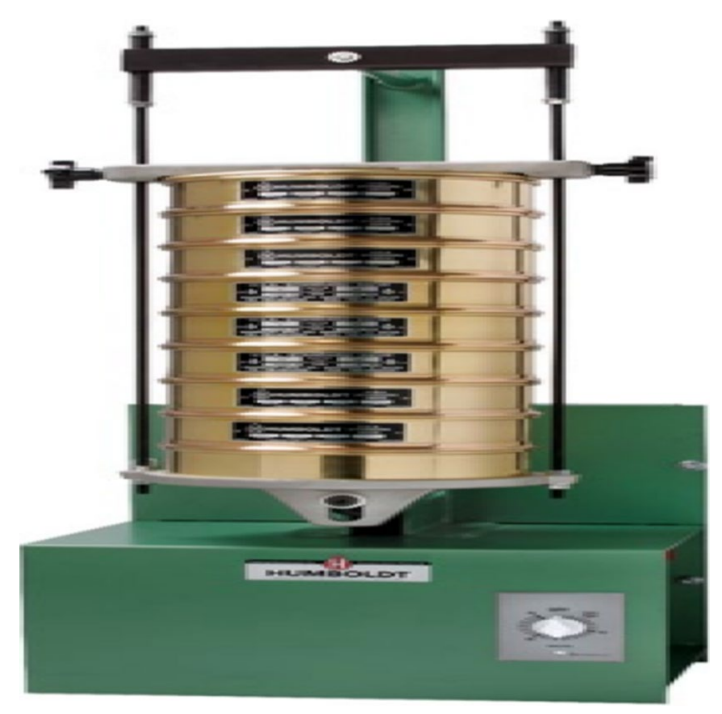

Fig. 2 Mechanical sieve shaker 


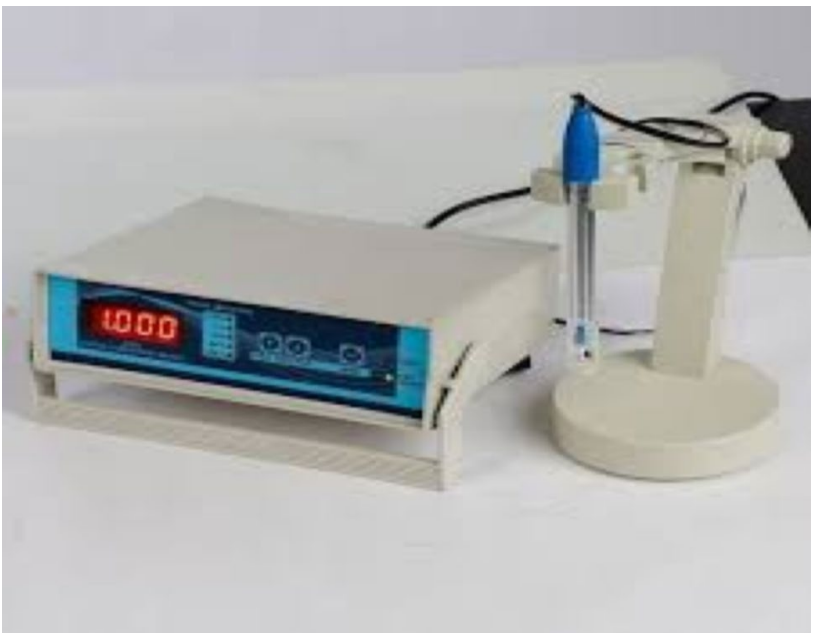

Fig. 3 A typical picture of digital $\mathrm{pH}$ meter

\section{$\mathrm{pH}$ measurement}

Measurement of sediment $\mathrm{pH}$ using a potentiometer determines the degree of acidity or alkalinity in sediment suspended in water and in $0.01 \mathrm{M}$ calcium chloride solution. The potentiometer is calibrated with buffer solutions of known $\mathrm{pH}$ prior to the analysis of samples. A typical picture of digital $\mathrm{pH}$ meter is shown in Fig. 3.

If the meter is calibrated using $\mathrm{pH} 4.00$ and $\mathrm{pH} 7.00$ buffers and the sample reading is $>7.00$, the meter must be recalibrated using pH 7.00 and 10.00 buffers. Likewise, if the meter is calibrated using 7.00 and 10.00 buffers and the $\mathrm{pH}$ reading is $<7.00$, the meter must be recalibrated using the 4.00 and 7.00 buffers. The sample $\mathrm{pH}$ will be displayed. Record the reading once the meter has stabilized (Kalra 1995). A 10-g air-dried sediment sample was taken in a paper cup. Then, $10 \mathrm{~mL}$ of deionizer water is added to sediment sample using pipette. After $5 \mathrm{~min}$, the solution is thoroughly mixed using a glass rod or mechanical stirrer. Let sediment $-\mathrm{H}_{2} \mathrm{O}$ suspension stand for $30 \mathrm{~min}$, and solution should be filtered using filter paper. Finally, $\mathrm{pH}$ of sediment sample was measured with help of $\mathrm{pH}$ probe.

\section{Electrical conductivity measurements}

The electrical conductivity (EC) of a solution is the measure of the ability of the solution to conduct electricity. The $\mathrm{EC}$ is reported in either millimhos per centimeter or the equivalent decisiemens per meter. A digital display electrical conductivity meter was used for measurements. A solution of $0.005 \mathrm{~N} \mathrm{KCl}$ has an electrical conductivity of $720 \pm 1$ $\mathrm{dS} / \mathrm{m}(\mathrm{mmho} / \mathrm{cm})$ at $25{ }^{\circ} \mathrm{C}$ prepared solution as the reference solution (Shivanna, and Nagendrappa 2014). Electrical conductivity meter was calibrated by above said reference solution. A typical picture of electrical conductivity meter is shown in Fig. 4.

Twenty-five grams of sediment sample should be mixed with $40 \mathrm{~mL}$ of deionizer water, resulting in water/soil ratio of 2:1. The 4-h equilibration period provides time for some slowly soluble constituents to approach solution equilibrium. Then, an electrode was inserted into solution to measure the conductivity of sample.

\section{Statistical analysis}

Statistical technique involving principal component analysis (PCA) was employed to identify the effects of physicochemical properties on the heavy metal, magnetic susceptibility, and natural radioactivity concentration. In addition, cluster analysis (CA) was performed to obtain information about the influence of the sediment properties to the studied parameters. Pearson correlations analysis was performed for studied variables with physicochemical properties to find out any existing relation between them. A computer code Statistical Package for Social Science (SPSS, version 16.0) was used in performing the statistical analyses.

\section{Results and discussion}

\section{Physicochemical parameters analysis}

The estimated results of the sand, silt, and clay and physicochemical parameters are present in Table 2. The sand percentages are found to vary between 0.1 and 0.83 , while the average of the sand percentage for overall the stations is $0.46 \%$. The high content in sand percentage in the samples (CPL) may indicate the high content of quartz, whereas the lowest percentage of sand observed for CPK

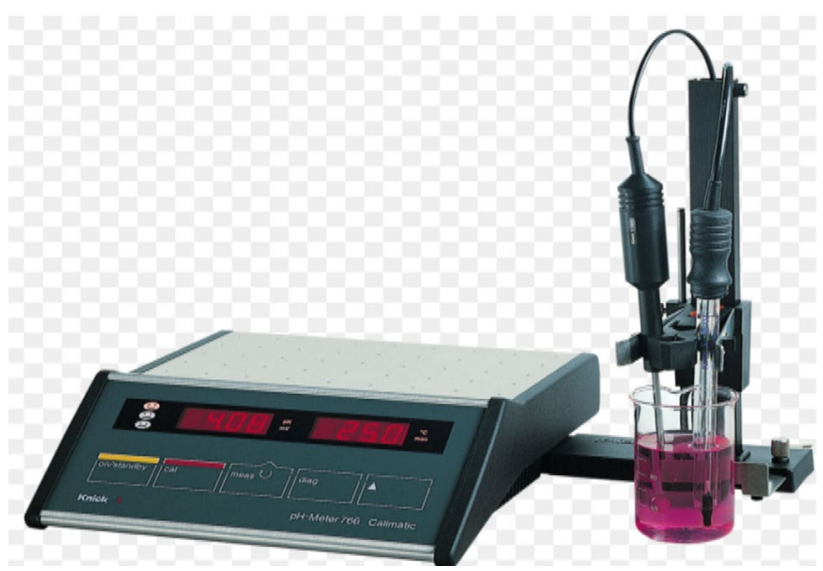

Fig. 4 A typical picture of electrical conductivity meter

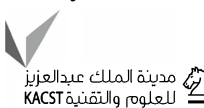


Table 2 Grain size analysis of physicochemical parameters of sediments of Chennai coast

\begin{tabular}{|c|c|c|c|c|c|c|}
\hline \multirow[t]{2}{*}{$\overline{\text { S.No }}$} & \multirow[t]{2}{*}{ Sample ID } & \multirow[t]{2}{*}{$\mathrm{pH}$} & \multirow[t]{2}{*}{$\mathrm{EC}\left(\mathrm{d} \mathrm{Sm}^{-1}\right)$} & \multicolumn{3}{|c|}{ Sediment texture } \\
\hline & & & & $\%$ Sand & $\%$ Silt & $\%$ Clay \\
\hline 01 & CPL & 6.96 & 0.524 & 0.83 & 97.39 & 1.78 \\
\hline 02 & CPK & 6.54 & 0.118 & 0.6 & 98.85 & 0.55 \\
\hline 03 & CKP & 6.02 & 0.526 & 0.26 & 97.71 & 2.03 \\
\hline 04 & CPS & 6.29 & 0.249 & 0.24 & 99.01 & 0.75 \\
\hline 05 & CNK & 6.14 & 0.377 & 0.18 & 95.68 & 4.14 \\
\hline 06 & CEE & 6.17 & 0.668 & 0.63 & 97.32 & 2.05 \\
\hline 07 & CTK & 6.40 & 0.590 & 0.62 & 98.27 & 1.11 \\
\hline 08 & $\mathrm{CCH}$ & 6.34 & 0.402 & 0.58 & 97.50 & 1.92 \\
\hline 09 & CPT & 6.39 & 0.446 & 0.25 & 97.16 & 2.59 \\
\hline 10 & $\mathrm{CKU}$ & 6.27 & 0.436 & 0.26 & 99.00 & 0.74 \\
\hline 11 & $\mathrm{CNB}$ & 6.45 & 0.278 & 0.43 & 98.74 & 0.83 \\
\hline 12 & $\mathrm{CMB}$ & 6.33 & 0.684 & 0.50 & 98.34 & 1.16 \\
\hline 13 & $\mathrm{CBB}$ & 6.50 & 0.339 & 0.45 & 98.83 & 0.72 \\
\hline 14 & $\mathrm{CBN}$ & 6.41 & 0.392 & 0.56 & 97.93 & 1.51 \\
\hline 15 & CTR & 6.23 & 0.550 & 0.80 & 98.68 & 0.52 \\
\hline 16 & $\mathrm{CNI}$ & 6.57 & 0.322 & 0.82 & 97.72 & 1.46 \\
\hline 17 & CCG & 6.44 & 0.433 & 0.46 & 98.39 & 1.15 \\
\hline 18 & CPR & 6.40 & 0.478 & 0.47 & 97.43 & 2.10 \\
\hline 19 & CKI & 6.55 & 0.327 & 0.13 & 98.48 & 1.39 \\
\hline 20 & CMK & 6.51 & 0.291 & 0.10 & 98.31 & 1.59 \\
\hline 21 & CKB & 6.33 & 0.618 & 0.28 & 97.87 & 1.85 \\
\hline 22 & CVM & 6.61 & 0.126 & 0.63 & 98.71 & 0.66 \\
\hline Average & & 6.40 & 0.42 & 0.46 & 98.06 & 1.48 \\
\hline
\end{tabular}

showed the low content of light minerals in the study area. The silt percentages vary from 95.68 to $99.01 \%$ with an average of $98.06 \%$. The high percentage of slit observed for CPK may be due to the primary minerals (Lal and Shukla 2004). Slit is the main constituent in all the sampling locations. The clay content ranges from 0.52 to $4.14 \%$ and has an average content of $1.48 \%$. This high content of clay in CPL indicates higher organic carbon in the sediment.

The $\mathrm{pH}$ measurement gives the nature of acidity or alkalinity. $\mathrm{pH}$ is defined as the negative logarithm of the activity of hydronium ions $\left(\mathrm{H}^{+}\right)$in a solution. $\mathrm{A} \mathrm{pH}$ below 7 is acidic and above 7 is alkaline. The values of $\mathrm{pH}$ measurements of all the locations showed acidic nature which indicated that quality of the sediment is not affected in the study area.

Electrical conductivity (EC) indicates the level of dissolved salts by measuring the capability of a solution to carry an electric current. The electrical conductivity (EC) ranged from 0 to $20,000 \mu \mathrm{S} / \mathrm{m}$ showed the non-saline nature. All the sediment samples had conductivity in the range from 0.118 to 0.684 indicating that the electrical conductivity does not affect the sediment quality.

\section{Multivariate statistical analysis (MCA)}

Multivariate statistical analysis (Pearson correlation, factor, and cluster analysis) was performed using SPSS 16.0 version and standardization of all sediments properties. Pearson correlation coefficients were determined to know the relation between magnetic susceptibility and physicochemical properties of sediments. Multivariate statistical techniques such as cluster analysis and factor analysis are essential tools in grouping materials according to their properties. Factor analysis (FA) helped to explain variance in the results. Using linear correlation variance of one sediment property from the entire samples is the key objective of this analytical process. A minimum of $40.82 \%$ of variation with an eigenvalue above 1 was observed. Clustering using hierarchical method proposed by Sneath and Sokal (1973) has been employed here. By grouping the sediments using dissimilarity coefficients by squared Euclidean distance method, the similarity patterns were studied. 
Table 3 Relation between magnetic parameters and physicochemical properties (Pearson correlation)

\begin{tabular}{|c|c|c|c|c|c|c|c|c|}
\hline Variables & $\chi \mathrm{LF}$ & $\chi \mathrm{HF}$ & $\% \chi \mathrm{FD}$ & $\%$ Sand & $\%$ Slit & \% Clay & $\mathrm{pH}$ & $\mathrm{EC}$ \\
\hline$\chi \mathrm{LF}$ & 1 & & & & & & & \\
\hline$\chi \mathrm{HF}$ & 1.000 & 1 & & & & & & \\
\hline$\% \chi \mathrm{FD}$ & -0.259 & -0.265 & 1 & & & & & \\
\hline$\%$ Sand & -0.175 & -0.174 & 0.101 & 1 & & & & \\
\hline$\%$ Slit & 0.274 & 0.276 & -0.185 & 0.054 & 1 & & & \\
\hline$\%$ Clay & -0.214 & -0.215 & 0.148 & -0.317 & -0.964 & 1 & & \\
\hline $\mathrm{pH}$ & -0.220 & -0.215 & 0.223 & 0.376 & 0.202 & -0.292 & 1 & \\
\hline $\mathrm{EC}$ & 0.071 & 0.069 & 0.175 & 0.133 & -0.327 & 0.275 & -0.358 & 1 \\
\hline
\end{tabular}

Bold values indicates positive correlations
Table 4 Factor loadings of magnetic parameters and physicochemical properties

\begin{tabular}{lrc}
\hline Variables & Factor-1 & Factor-2 \\
\hline$\chi \mathrm{LF}$ & $\mathbf{0 . 9 9 3}$ & 0.118 \\
$\chi \mathrm{HF}$ & $\mathbf{0 . 9 9 4}$ & 0.111 \\
$\% \chi \mathrm{FD}$ & -0.370 & $\mathbf{0 . 9 1 6}$ \\
$\%$ Sand & -0.176 & 0.005 \\
$\%$ Slit & $\mathbf{0 . 2 8 9}$ & -0.102 \\
$\%$ Clay & -0.227 & 0.096 \\
pH & -0.223 & 0.033 \\
EC & 0.044 & $\mathbf{0 . 2 2 8}$ \\
$\%$ of variance explained & $\mathbf{2 9 . 1 0 0}$ & $\mathbf{1 1 . 7 2 0}$ \\
\hline
\end{tabular}

Bold values indicates significant loadings of variables

\section{Relation between physicochemical properties and magnetic measurements}

A physicochemical property is important physical indicator of sediment environment. In particular, grain size analysis is a good indicator of magnetic property variations in sediments. Hence, in order to understand the variations in magnetic properties, the Pearson correlation coefficient determined and presented in Table 3 .

As seen from Table 3, a positive correlation was observed between high-frequency susceptibility and \% slit electrical conductivity. This indicates that concentration of slit and conductivity increases the magnetic property of sediments. At the same time, negative correlation was observed between $\%$ sand, \% clay, and $\mathrm{pH}$ with high-frequency susceptibility, which suggests that magnetic parameters in sediments tend to decreases with decreasing grain size.

In order to ensure the positive and negative correlations, factor analysis was carried between magnetic and physicochemical variables by Varimax-normalized rotation. The rotated factor loadings of variables are given in Table 4. Factor analysis has extracted two factors. The factors 1 and 2 account for $40.82 \%$ of total variance. Factor 1 was characterized by positive loadings of $\%$ slit, electrical

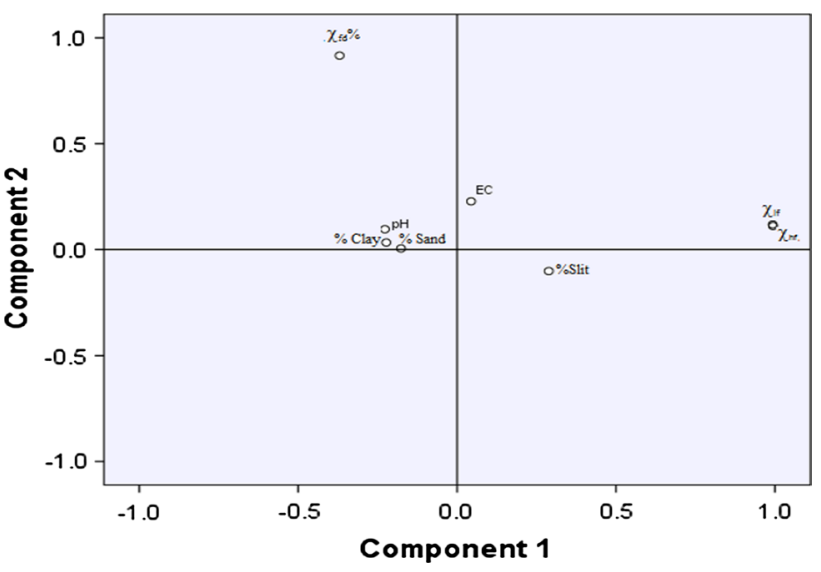

Fig. 5 Rotated factor loadings of physicochemical and magnetic variables



Fig. 6 Clustering of physicochemical and magnetic variables

conductivity, and low- and high-frequency susceptibility of sediments with $29.10 \%$ of variance, whereas factor 2 was loaded by concentrations of $\%$ sand, $\%$ clay, $\mathrm{pH}$, and $\%$ FD of sediments with $11.72 \%$ of variance. The factor 1 signifies the association of slit percentage of sediment and magnetic minerals in the sediments. These results are good agreement with correlation analysis. A rotated two-dimensional factor loadings of variables are shown in Fig. 5. 


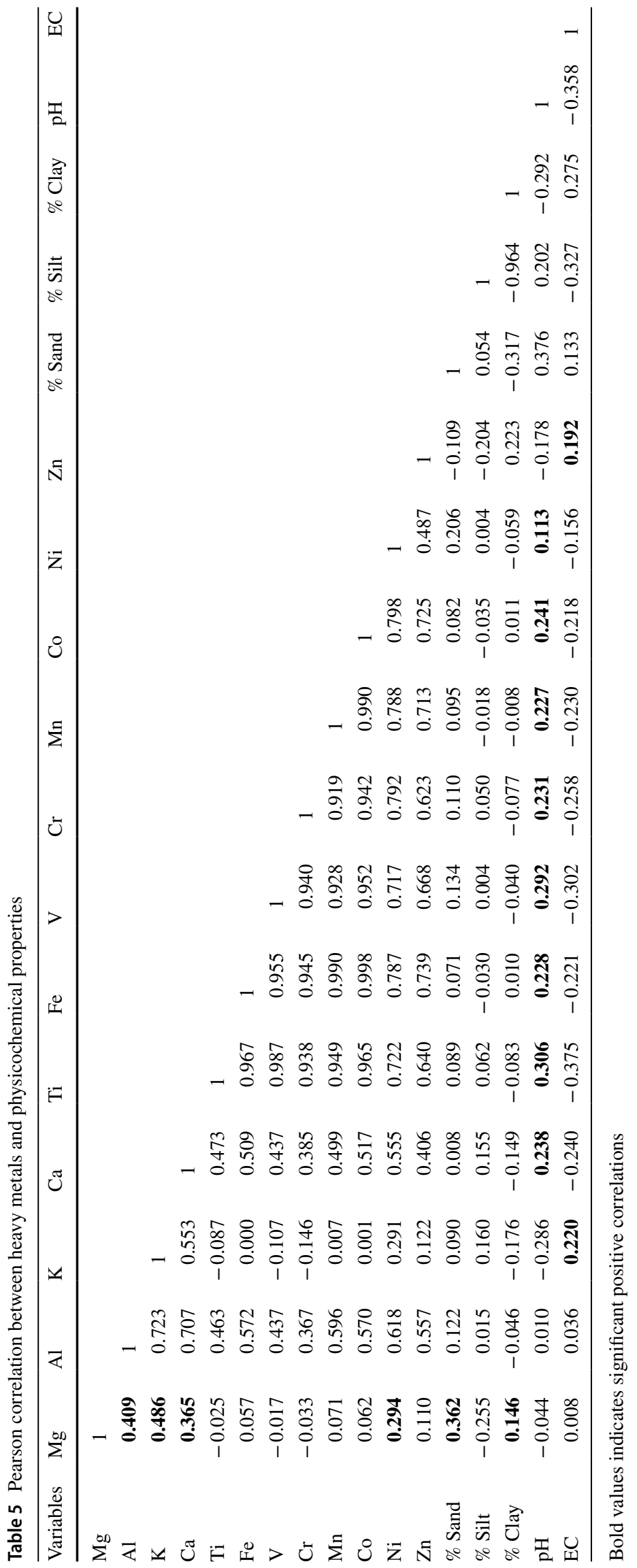


Table 6 Factor analysis of physicochemical and heavy metal variables

\begin{tabular}{lrr}
\hline Variables & Factor-1 & Factor-2 \\
\hline $\mathrm{Mg}$ & -0.030 & 0.514 \\
$\mathrm{Al}$ & 0.453 & $\mathbf{0 . 8 5 9}$ \\
$\mathrm{K}$ & -0.135 & $\mathbf{0 . 8 9 9}$ \\
$\mathrm{Ca}$ & 0.430 & $\mathbf{0 . 7 3 9}$ \\
$\mathrm{Ti}$ & $\mathbf{0 . 9 8 1}$ & 0.036 \\
$\mathrm{Fe}$ & $\mathbf{0 . 9 8 9}$ & 0.137 \\
$\mathrm{~V}$ & $\mathbf{0 . 9 7 1}$ & 0.006 \\
$\mathrm{Cr}$ & $\mathbf{0 . 9 6 1}$ & -0.064 \\
$\mathrm{Mn}$ & $\mathbf{0 . 9 7 5}$ & 0.159 \\
$\mathrm{Co}$ & $\mathbf{0 . 9 8 7}$ & 0.140 \\
$\mathrm{Ni}$ & $\mathbf{0 . 7 3 8}$ & 0.337 \\
Zn & $\mathbf{0 . 6 9 9}$ & 0.242 \\
\% Sand & $\mathbf{0 . 0 5 7}$ & 0.081 \\
\% Silt & -0.021 & $\mathbf{0 . 0 8 3}$ \\
\% Clay & $\mathbf{0 . 0 0 5}$ & -0.100 \\
pH & $\mathbf{0 . 2 6 6}$ & -0.056 \\
EC & -0.272 & $\mathbf{0 . 0 9 0}$ \\
\% of variance explained & $\mathbf{3 7 . 8 8 0}$ & $\mathbf{2 0 . 6 7 0}$ \\
\hline
\end{tabular}

Bold values indicates significant loadings of variables

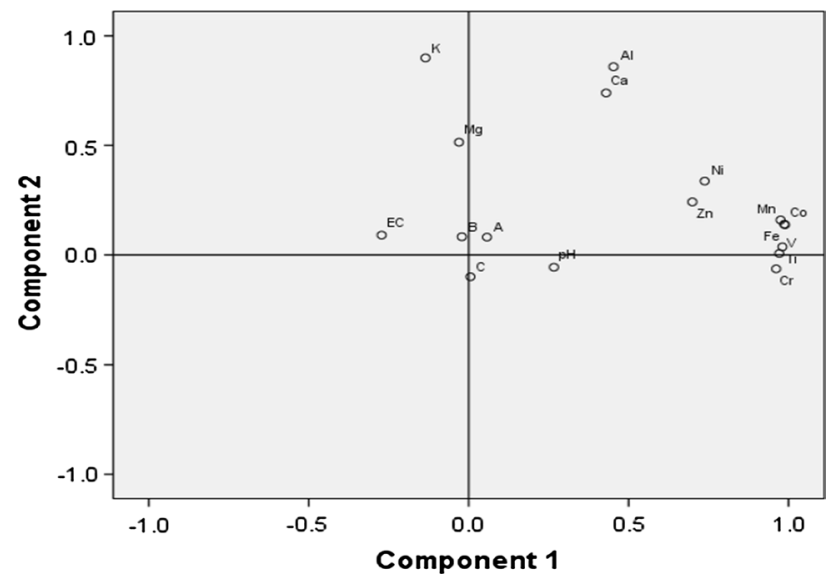

Fig. 7 Rotated factor loadings of physicochemical and heavy metals

Cluster analysis was carried out to know the similarity between the variables. Two clusters are formed based on the similarities of variables and are shown in Fig. 6. Cluster I contains $\%$ sand. $\%$ clay, slit, $\mathrm{pH}$, conductivity, and \% FD, which indicates that the concentration of magnetic minerals in sediments depends on the physicochemical properties. Cluster II contains low- and high-frequency susceptibilities. This indicates that the low- and high-frequency susceptibilities are inter-related.

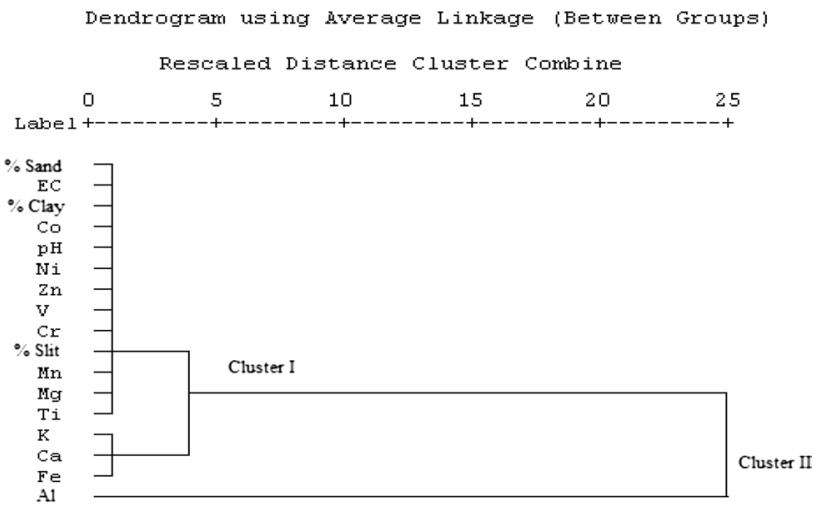

Fig. 8 Clustering of physicochemical and heavy metal variables

\section{Relationship between heavy metals and physicochemical properties}

In order to identify correlation between metal concentrations and other physicochemical parameters, the Pearson correlation matrix was used. $\mathrm{Mg}, \mathrm{Al}, \mathrm{K}, \mathrm{Ca}, \mathrm{Fe}, \mathrm{Cr}, \mathrm{Mn}, \mathrm{Co}, \mathrm{Ni}$, and $\mathrm{Zn}$ had a positive correlation $(p<0.01)$ with the other sediments.

Some unique correlation was observed in the physicochemical properties as shown in the correlation matrix in Table 5. Metals such as $\mathrm{Mg}, \mathrm{Al}, \mathrm{K}, \mathrm{Ca}, \mathrm{Ni}$, and $\mathrm{Zn}$ displayed positive correlation $(p<0.01)$ with $\%$ sand and $\%$ clay. On the other hand, it had reverse effect on $\%$ silt and $\mathrm{pH}$ $(p<0.01)$. An increase in metal concentration could cause an increase in the percentage.

To prepare quality indices, factor analysis-a multivariate statistical method-has been used in this study. A smaller group of factors substituted for the initial set of variables to ensure much information of the original variables is possibly preserved. Using factor analysis, an index is constructed for variability with smaller and simpler vectors from the original data (Lin et al. 2002). In factor analysis, a correlation matrix is first prepared between the variables. The extraction of factors with appropriate rotation seeks a final solution that is easier to understand. In the beginning, all the variables are treated equal, but after the correlation is carried out, the final quality is expressed in the environmental situation.

The use of this technique is largely helpful to study the relationship between variables and understand its significance in the environment over space and time. This analysis helps to identify hidden trends associated with sediment dynamics. Factor analysis between physicochemical and heavy metal variable was also done in this study.

The result are given in Table 6, and it depicts the factor loading and the two principal components associated with different variables responsible for their contribution. Figure 7 shows the factor loading of physicochemical and heavy metals. A $37.88 \%$ is obtained for the factor I. A better 
correlation is seen in total and partial Fe, total $\mathrm{Ni}$, total $\mathrm{Mn}$ and partial sand, total $\mathrm{Cr}$, total $\mathrm{Ti}$ and partial clay, and total and partial V. Hence $20.67 \%$ of variance was observed with total $\mathrm{Al}, \mathrm{Ca}, \mathrm{K}$, and partial $\mathrm{EC}$ at the most. The potential contribution of physicochemical properties is seen in the correlation of these parameters.

\section{Cluster analysis}

Figure 8 shows the cluster diagram of physicochemical parameters with heavy metals. Cluster analysis for mean elements could be grouped into two clusters or groups. $\%$ sand, EC, \% clay, Co, pH, Ni, Zn, V, Cr, \% slit, Mn, Mg, Ti, $\mathrm{K}, \mathrm{Ca}$, and $\mathrm{Fe}$ have good similarity and are clustered in one group,. Only Al was clustered in another group. Strong similarity between heavy metal and physicochemical properties showed origin of these metals varies from physicochemical properties.

\section{Relation between radionuclides and physicochemical properties}

\section{Pearson correlation analysis}

In order to analyze the relation between radionuclides and physicochemical properties in sediments, a Pearson correlations analysis was performed for variables. Table 7 presents the correlation coefficients $(r)$ of natural radioactive concentrations detected in sediments and physicochemical properties. Using a Pearson correlation coefficient, significant positive relation was found between Th and $\%$ sand $(r=0.112)$ and $\%$ slit $(r=0.194)$. Also, a negative relationship was observed between Th and ( $r=-0.417$ ) electrical conductivity (EC). The findings also showed that a good positive correlation between $\mathrm{U}$ and $\mathrm{pH}(r=0.279)$. Barisic et al. (1998) reported that the distribution of uranium and thorium in sediments is strongly influenced and governed by grain-size distribution.

Therefore, reasonable positive correlation was detected between the values of $\mathrm{pH}$, uranium $(r=0.279)$, and thorium $(r=0.385)$. This indicated that the physicochemical properties are considered as one of the important factors describing the radioactivity contents of the sediments.

\section{Factor analysis}

Principal component analysis and hierarchical cluster analysis are good methods in grain size analysis and study of radioactive variable in sediments.

For standard recognition, PCA is applied to explain the discrepancies between a number of correlated variables. The linear combination variables are obtained in PCA using orthogonal transformation which is an effective dimension reduction technique. The principal components are the new variables, and they are smaller than the original variables, and hence the PCAs are uncorrelated, and they retain most variations in the first few components. A score plot is an excellent tool that displays the relationship between objects looking for groups, trends, sorts, and outlines. Also the loading plots help in sample classification.

The analysis generated two factors which together account for $40.22 \%$ of the total variance. The rotated loadings, percentage of variance, and cumulative percentage of two factors are given in Table 8 .

The first factor accounts for $27.39 \%$ of the total variance and is characterized by high loadings of $\mathrm{U}, \mathrm{Th}$, and $\mathrm{pH}$. This indicates that $\mathrm{U}$ and $\mathrm{Th}$ may be associated with $\mathrm{pH}$ in sediments found in the area. This constitutes the first and main factor. The second factor accounts for $12.830 \%$ of the

Table 8 Factor analysis of radioactive and physicochemical variables

\begin{tabular}{lrr}
\hline Variables & Factor-1 & Factor-2 \\
\hline $\mathrm{U}$ & $\mathbf{0 . 8 8 4}$ & 0.104 \\
$\mathrm{Th}$ & $\mathbf{1 . 0 0 0}$ & -0.012 \\
$\mathrm{~K}$ & -0.067 & $\mathbf{0 . 9 9 8}$ \\
\% Sand & 0.112 & 0.109 \\
\% Slit & 0.187 & 0.036 \\
\% Clay & -0.208 & -0.063 \\
$\mathrm{pH}$ & $\mathbf{0 . 3 8 2}$ & -0.029 \\
EC & -0.412 & -0.044 \\
\% of variance explained & 27.390 & 12.830 \\
\hline
\end{tabular}

Table 7 Pearson correlation analysis of radioactive and physicochemical variables

\begin{tabular}{lrrrrrrrr}
\hline Variables & \multicolumn{1}{l}{$\mathrm{U}$} & \multicolumn{1}{c}{$\mathrm{Th}$} & $\mathrm{K}$ & \% Sand & \% Slit & \% Clay & $\mathrm{pH}$ & $\mathrm{EC}$ \\
\hline $\mathrm{U}$ & 1 & & & & & & & \\
$\mathrm{Th}$ & $\mathbf{0 . 8 7 3}$ & 1 & & & & & & \\
$\mathrm{~K}$ & 0.044 & -0.078 & 1 & & & & & \\
\% Sand & 0.066 & 0.112 & 0.102 & 1 & & & & \\
\% Slit & 0.012 & 0.194 & 0.024 & 0.054 & 1 & & & \\
\% Clay & -0.029 & -0.214 & -0.049 & -0.317 & -0.964 & 1 & & \\
pH & $\mathbf{0 . 2 7 9}$ & $\mathbf{0 . 3 8 5}$ & -0.054 & 0.376 & 0.202 & -0.292 & 1 & \\
EC & -0.224 & -0.417 & 0.017 & 0.133 & 0.327 & 0.275 & 0.358 & 1 \\
\hline
\end{tabular}




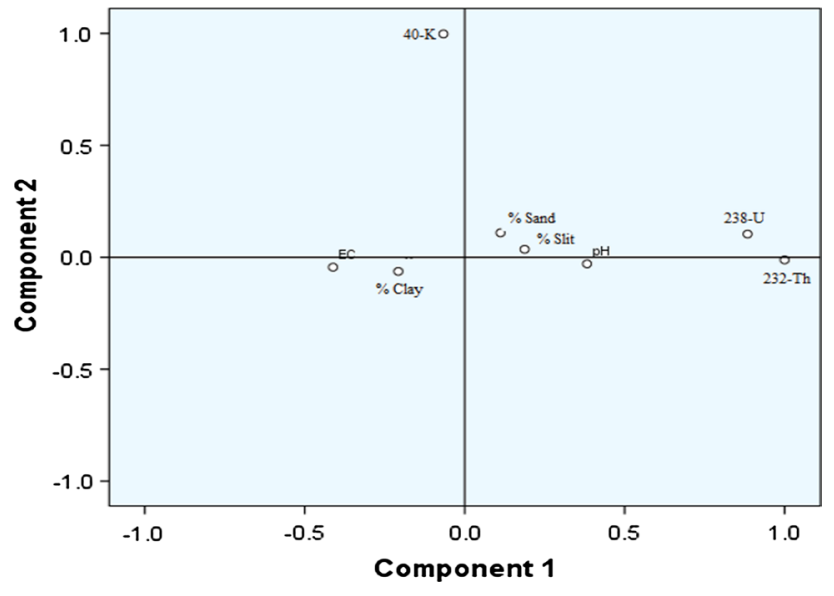

Fig. 9 Rotated components of variables and radioactivity

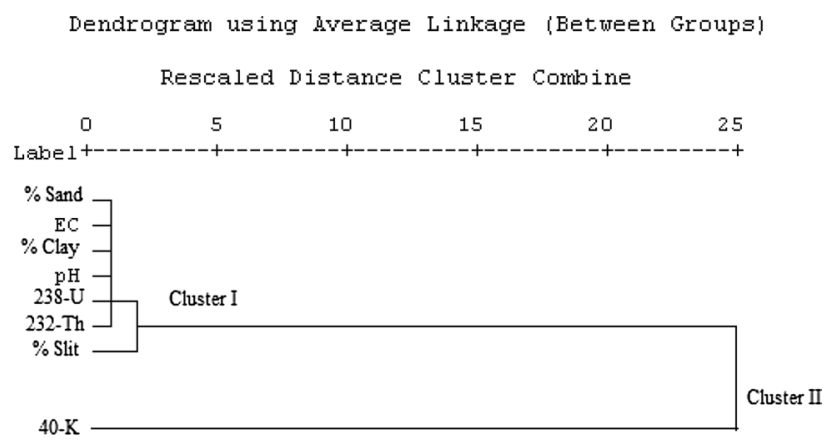

Fig. 10 Dendrogram of radioactive variables

total variance and is characterized by high loadings of $\mathrm{K}$ and partial \% slit. These two factors indicate that variation of activity concentration is due to physicochemical properties. Figure 9 shows that rotated components of variables.

\section{Hierarchical cluster analysis (HCA)}

The mean or the K-neighbor of the samples has been taken into account to find the distance between the sample data in the process of HCA. Often PCA-generated scores or scaled original data are used to HCA. The samples are classified into homogeneous groups based on some criteria, and a numerical method is adopted. A dendrogram shown in Fig. 10 is plotted based on the distance calculations done.

Cluster I contains \% sand, EC, \% clay, $\mathrm{pH},{ }^{238} \mathrm{U},{ }^{232} \mathrm{Th}$, $\%$ slit, whereas cluster II contains only ${ }^{40} \mathrm{~K}$. From the cluster analysis result, it can be said that there is a strong correlation between radionuclides and physicochemical pair, which is a good agreement with factor, but cluster analysis results did not show a good agreement between $\mathrm{K}$ and physicochemical properties pair. This result suggests that the strong relationship between activity concentration and physicochemical properties.

\section{Conclusion}

The obtained results of magnetic parameters with the physicochemical parameters in sediments showed that its value decreases in grain size. The heavy metal analysis with physicochemical parameters indicated that the increase in metal concentration leads to raise of percentage of sediment texture values. The natural radioactivity concentration with physicochemical parameters analysis suggested that the strong relationship between them.

With the results obtained, it can be concluded that both spectroscopy and multivariate analysis can be used in conjunction effectively. The use of texture analysis helps largely in studying sediment properties more easily. This in turn aids studies in several areas of agriculture, mineralogy, and geophysics.

Acknowledgements One of the author (R. Ravisankar) wishes to express his high gratitude to Dr. B. Venkatraman, Director, Radiation Safety \& Environmental Group, Indira Gandhi Centre for Atomic Research (IGCAR), Kalpakkam, Tamilnadu India for his constant support and encouragements in environmental studies and Pollution analysis.

Open Access This article is distributed under the terms of the Creative Commons Attribution 4.0 International License (http://creativeco mmons.org/licenses/by/4.0/), which permits unrestricted use, distribution, and reproduction in any medium, provided you give appropriate credit to the original author(s) and the source, provide a link to the Creative Commons license, and indicate if changes were made.

\section{References}

Barisic D, Vertacnik A, Lulic S, Mihelcic G, Sondi I, Juracic M, Prohic E, Crmaric R (1998) Natural radionuclides in recent marine sediments of the Adriatic sea. Rapp Commun Int Mer Medit $35: 228-229$

Blatt H, Middleton G, Murray R (1972) Origin of sedimentary rocks. Prentice-Hall, Englewood Cliffs, p 634

Ingham AE (1975) Sea surveying. Wiley, London. ISBN-10: 0471427292

Kalra YP (1995) Determination of pH of Soils by different methods: collaborative study. J AOAC Int 78(2):310-322

Lal R, Shukla MK (2004) Principles of soil physics. Marcel Dekker, New York

Lin YP, Teng TP, Chang TK (2002) Multivariate analysis of soil heavy metal pollution and landscape pattern in Changhua county in Taiwan. Landscape and Urban Planning 62:19-35

McCave IN, Syvitski JPM (1991) Principles and methods of particle size analysis. In: Syvitski JPM (ed) Principles, methods, and applications of particle size analysis. Cambridge University Press, New York, pp 3-21 
Melquiades FL, González-Borrero PP, Dos Santos FR, De Deus WED, Kalwa M, Quináia SP (2014) Method for sediment texture characterization using spectroscopy techniques and multivariate analysis. Rev Virtual Quim. 6(6):1687-1701

Paramasivam K, Ramasamy V, Suresh G (2015) Impact of sediment characteristics on the heavy metal concentration and their ecological risk level of surface sediments of Vaigai river, Tamilnadu, India. Spectrochim Acta Part A Mol Biomol Spectrosc 137:397-407

Ramasamy V, Paramasivam K, Suresh G, Jose MT (2014) Role of sediment characteristics on natural radiation level of the Vaigai river sediment, Tamilnadu, India. J Environ Radioact 127:64-74

Ravisankar R, Chandrasekaran A, Kalaiarasi S, Eswaran P, Rajasekhar C, Vanasundari K, Athavale Alok (2011) Mineral analysis in beach rocks of Andaman Island, India by spectroscopic techniques. Arch Appl Sci Res 3:77-84

Ravisankar R, Sivakumar S, Chandrasekaran A, Kanagasabapathy KV, Prasad MVR, Satapathy KK (2015) Statistical assessment of heavy metal pollution in sediments of east coast of Tamilnadu using energy dispersive X-ray fluorescence spectroscopy (EDXRF). Appl Radiat Isot 102:42-47

Shivanna AM, Nagendrappa G (2014) Chemical analysis of soil samples to evaluate the soil fertility status of selected command areas of three tanks in Tiptur Taluk of Karnataka, India. IOSR J Appl Chem 7(11):01-05

Sly PG (1969) Bottom sediment sampling. In: Proceedings of the 12th conference on Great Lakes Research, Buffalo, NY: International Association for Great Lakes Research, pp 883-898

Sneath PHA, Sokal RR (1973) Numerical taxonomy: the principles and practice of numerical classification. Freeman, San Francisco, p 573

Sonaye SY, Baxi RN (2012) Particle size measurement and analysis of flour. Int J Eng Res Appl 2(3):1839-1842

Suresh G, Ramasamy V, Meenakshisundaram V, Venkatachalapahty R, Ponnusamy V (2011) Influence of mineralogical and heavy metal composition on natural radionuclide concentrations in the river sediments. Appl Radiat Isot 69:1466-1474

Publisher's Note Springer Nature remains neutral with regard to jurisdictional claims in published maps and institutional affiliations. 